\title{
The age pattern of the male-to-female ratio in mortality from COVID- 19 mirrors that of cardiovascular disease in the general population
}

\author{
Ila Nimgaonkar ${ }^{1}$, Linda Valeri' ${ }^{2}$, Ezra Susser $^{3,4}$, Sabiha Hussain $^{5}$, Jag Sunderram ${ }^{5}$, Abraham Aviv $^{6}$ \\ ${ }^{1}$ Robert Wood Johnson Medical School, Rutgers State University of New Jersey, New Brunswick, NJ 08901, USA \\ ${ }^{2}$ Department of Biostatistics, Mailman School of Public Health, Columbia University, New York, NY 10032, USA \\ ${ }^{3}$ Mailman School of Public Health, Columbia University, New York, NY 10032, USA \\ ${ }^{4}$ New York State Psychiatric Institute, New York, NY 10032, USA \\ ${ }^{5}$ Department of Medicine, Robert Wood Johnson Medical School, Rutgers State University of New Jersey, New \\ Brunswick, NJ 08901, USA \\ ${ }^{6}$ Center of Human Development and Aging, New Jersey Medical School, Rutgers State University of New Jersey, \\ Newark, NJ 07103, USA
}

Correspondence to: Ila Nimgaonkar; email: ila.nimgaonkar@gmail.com, https://orcid.org/0000-0003-0646-6517 Keywords: COVID-19, mortality, age, sex, cardiovascular disease

Received: November 16, 2020 Accepted: January 22, 2021

Published: February 7, 2021

Copyright: (c) 2021 Nimgaonkar et al. This is an open access article distributed under the terms of the Creative Commons Attribution License (CC BY 3.0), which permits unrestricted use, distribution, and reproduction in any medium, provided the original author and source are credited.

\section{ABSTRACT}

Males are at a higher risk of dying from COVID-19 than females. Older age and cardiovascular disease are also associated with COVID-19 mortality. To better understand how age and sex interact in contributing to COVID-19 mortality, we stratified the male-to-female (sex) ratios in mortality by age group. We then compared the agestratified sex ratios with those of cardiovascular mortality and cancer mortality in the general population. Data were obtained from official government sources in the US and five European countries: Italy, Spain, France, Germany, and the Netherlands. The sex ratio of deaths from COVID-19 exceeded one throughout adult life, increasing up to a peak in midlife, and declining markedly in later life. This pattern was also observed for the sex ratio of deaths from cardiovascular disease, but not cancer, in the general populations of the US and European countries. Therefore, the sex ratios of deaths from COVID-19 and from cardiovascular disease share similar patterns across the adult life course. The underlying mechanisms are poorly understood and warrant further investigation.

\section{INTRODUCTION}

More males than females die from COVID-19, the disease caused by SARS-CoV-2. This was first observed in China, where 64\% of COVID-19 deaths occurred in males [1]. As the epidemic spread worldwide, other countries similarly observed a higher percentage of deaths from COVID-19 in males [1]. The higher number of deaths among males is consistent with mortality patterns observed in several major viral epidemics/pandemics of the $20^{\text {th }}$ and $21^{\text {st }}$ centuries, including the Western African Ebola virus epidemic (2013-2016) [2] and the H1N1 Spanish Flu pandemic of 1918 [3]. Adult men also have an overall higher mortality rate than adult women from seasonal influenza based on data in the US between 1997-2007, with some variation depending on age group and underlying conditions [4].

In contrast, COVID-19 mortality by age differs from other viral pandemics. More than $80 \%$ of COVID-19 deaths in the US and European countries have occurred in adults older than 65 years [5], with very few deaths in young children [6]. Seasonal influenza causes relatively more pediatric deaths, especially in infants under the age of six months [7], in addition to a disproportionate number of deaths in older adults over the age of 65 years [8]. Several major viral pandemics of the $20^{\text {th }}$ and 
$21^{\text {st }}$ centuries have also shown different age-based mortality patterns from COVID-19. For instance, in the Spanish Flu of 1918 a large proportion of deaths were in young adults [9], and in the 2009 H1N1 influenza pandemic a large proportion occurred in children and adults under 60 years [10]. Therefore, COVID-19 mortality trends are consistent with sex-based, but not with age-based patterns seen in many other viral pandemics.

In searching for explanations for the distinctive pattern of deaths in COVID-19, we first examined variation by age group in the male-to-female (sex) ratio of mortality in data from the US and five European countries. Given that cardiovascular disease (CVD) has been strongly associated with increased risk of mortality in COVID19 [11], we next examined variation in the sex ratio of CVD mortality by age group in the same countries. As CVD and cancer are the two major age-related disease categories that largely determine survival of adults in middle-and-high income societies [12], we further examined variation by age in the sex ratio of cancer mortality. Here we report our findings and offer potential explanations regarding their meaning.

\section{RESULTS}

Stratified by age, and adjusted for population at risk in each age group (Supplementary Figure 1, Supplementary Table 2), the sex ratios for COVID-19 deaths among adults in the US and five European countries (Italy, Spain, France, Germany, and the Netherlands) showed similar overall patterns, initially rising to a peak in midlife and then falling (Figure 1). Specifically, the sex ratio of mortality peaked between the ages of 35-44 years in the US and 60-69 years in the European countries, and then progressively declined at older ages without dropping below one.

We next examined the sex ratio of CVD mortality by age in these countries (Figure 2, Supplementary Figure 2). The sex ratio for CVD mortality initially rose to a peak in midlife and then declined, in both the US and Europe. For ages younger than 70 years, the sex ratio for CVD mortality in Europe was higher than in the US.

As cancer is the other leading cause of adult mortality in the US and Europe [13], we also examined the sex ratio for cancer mortality by age (Figure 3, Supplementary Figures 3, 4). The sex ratio for cancer mortality increased after midlife with no evidence of decline thereafter.

When the sex ratios of mortality by age for COVID19, CVD and cancer were overlaid, the COVID-19 profile mirrored that of CVD, although, the sex ratio for CVD was much higher in Europe than the US for ages younger than 70 years (Figure 4). The profile of the sex ratio by age for cancer mortality, however, clearly differed from the ratios for COVID-19 and for CVD.

\section{DISCUSSION}

\section{General considerations}

Our key findings are as follows: (i) for all age groups, the death rate from COVID-19 was higher in males than females; (ii) the sex mortality ratio for COVID-19 rose to a peak in midlife and then narrowed with increasing age; and (iii) the sex mortality ratio for COVID-19 by age mirrored that for CVD but not cancer. Since the COVID-19 data were not linked to population databases with individual-level health information, we could not specifically examine the potential contribution of CVD to the age pattern of the sex mortality ratio from COVID-19. We propose, nonetheless, based on data displayed in Figure 4, that the sex ratio for COVID-19 mortality, particularly for adults older than 60 years, might partially reflect the mechanisms that drive the age pattern of the sex mortality ratio for CVD in the general population.

What then might be these mechanisms? The underlying biological reasons are likely multifactorial and complex. We review several potential explanations: pre-existing cardiovascular risk factors, sex hormones, and $\mathrm{X}$ chromosome mosaicism.

\section{Cardiovascular risk factors}

Early available clinical data suggest that patients who become critically ill from COVID-19 are more likely to have pre-existing CVD risk factors such as hypertension and diabetes than patients who experience a milder disease course [14, 15]. Certain CVD risk factors also show different prevalence rates among males and females. For example, hypertension rates are higher in males than in females under the age of 60 , but are not significantly different at ages 60 and over [16]. Males also have higher rates of both diagnosed and undiagnosed cases of diabetes, and typically develop atherosclerotic disease earlier than females [17]. These patterns for hypertension and atherosclerotic disease, which occur at higher rates in younger males and at more equal rates at older ages, share similarities with the sex ratios observed for COVID-19 and CVD mortality, and may partially explain the age pattern of the sex ratio in COVID-19 mortality. Though suggestive by our findings, definitive studies are needed to establish direct links between CVD risk factors and COVID-19 mortality. 
Sex hormones: estrogens and androgens

Endogenous estrogens have been associated with a protective effect against CVD in premenopausal women [18], while predisposing women to certain cancers [19].
Higher estrogen [20] and progesterone [21] levels in premenopausal women might also modulate immune responses and attenuate the severity of COVID-19. In this regard, data from the US show a decline in the sex ratio of COVID-19 mortality after ages 45-54 years,
A

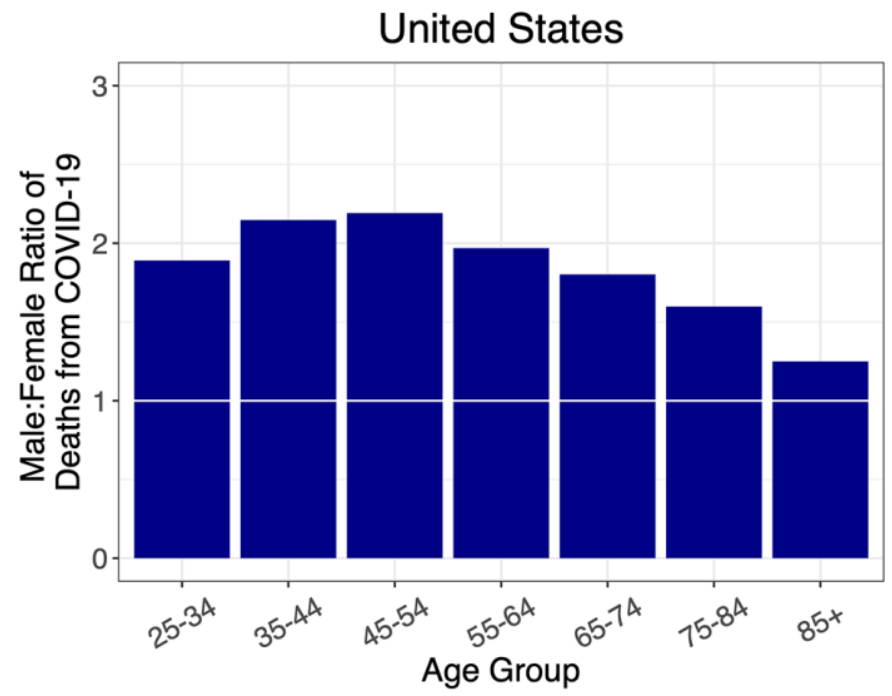

B

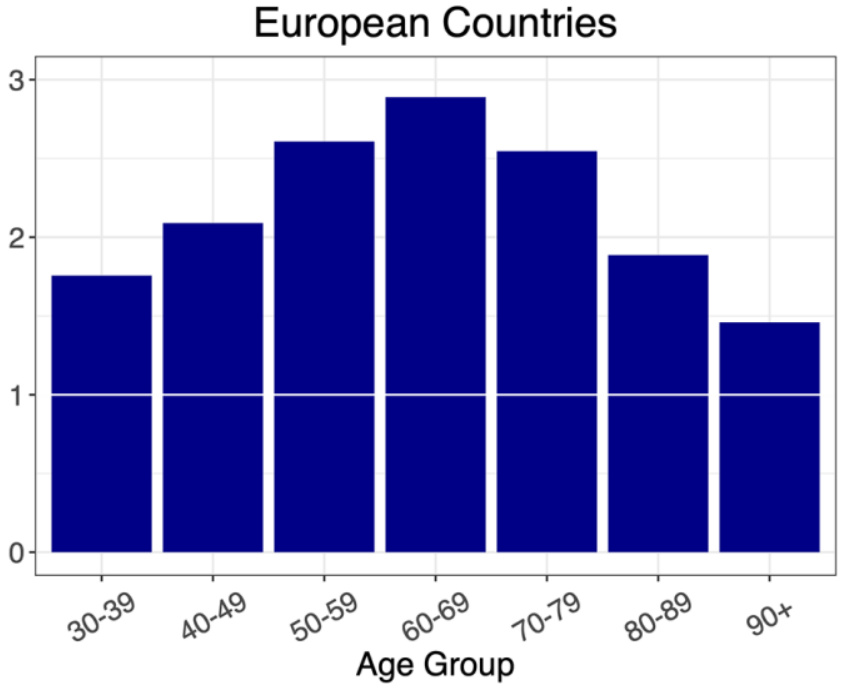

Figure 1. Ratios of male to female deaths from COVID-19 (adjusted for population sex distribution) for (A) the US, and (B) combined ratios for five European countries: Italy, France, Spain, Germany, and the Netherlands. A 1:1 ratio is indicated by white markers.

A

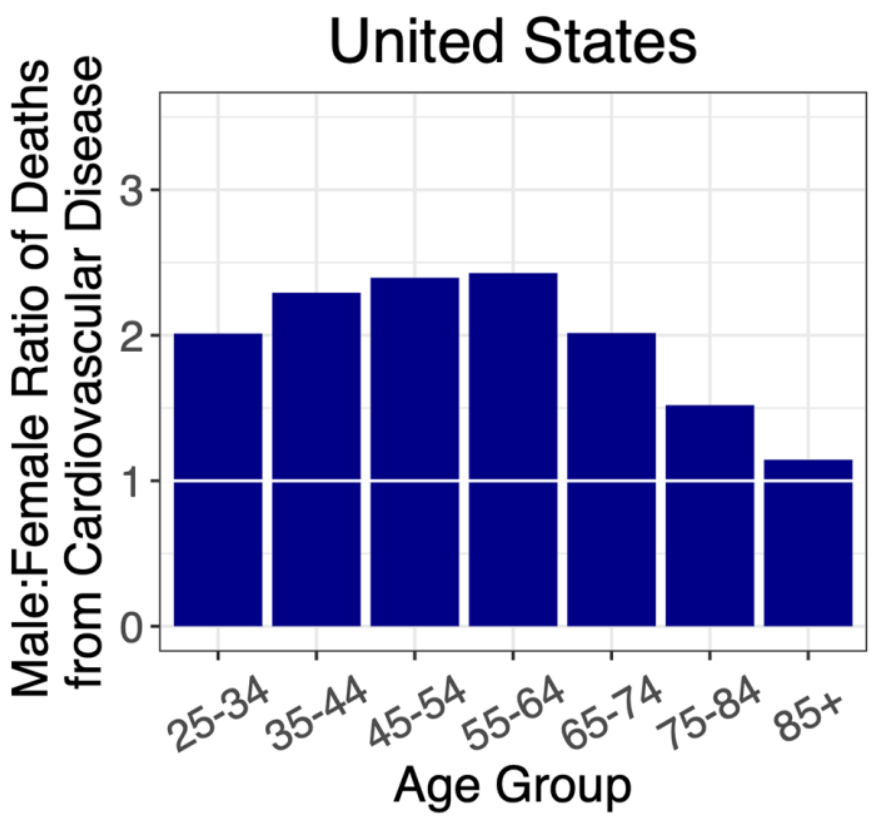

B

\section{European Countries}

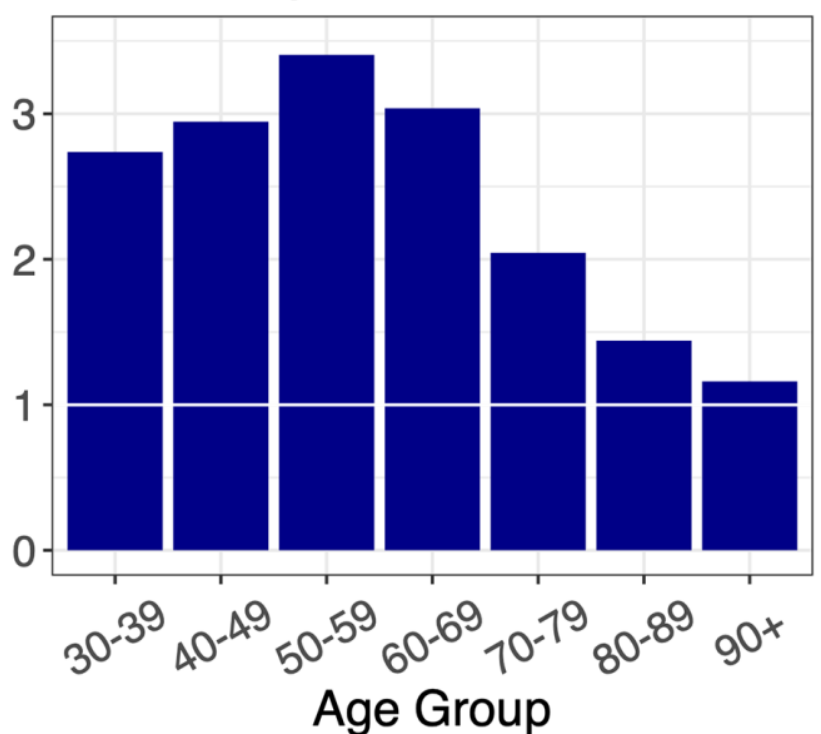

Figure 2. Ratios of male to female deaths from cardiovascular disease (adjusted for population sex distribution) for (A) the US, and (B) combined ratios for the European countries: Italy, France, Spain, Germany, and the Netherlands. A 1:1 ratio is indicated by white horizontal lines. 
which coincides with the average age that women undergo menopause [22]. However, the data from the European countries show a drop in the sex ratio of COVID-19 mortality starting in the 60-69-year age group- later than the average age of menopause. Clinical trials are currently investigating whether estrogen or progesterone treatment can alleviate
COVID-19 symptoms, which may provide more clarity to the role of ovarian hormones in COVID-19 pathogenesis (https://www.clinicaltrials.gov/ identifiers NCT04359329, NCT04365127).

Androgen increases the expression of TMPRSS2 [23], a gene encoding Type II Transmembrane Serine Protease

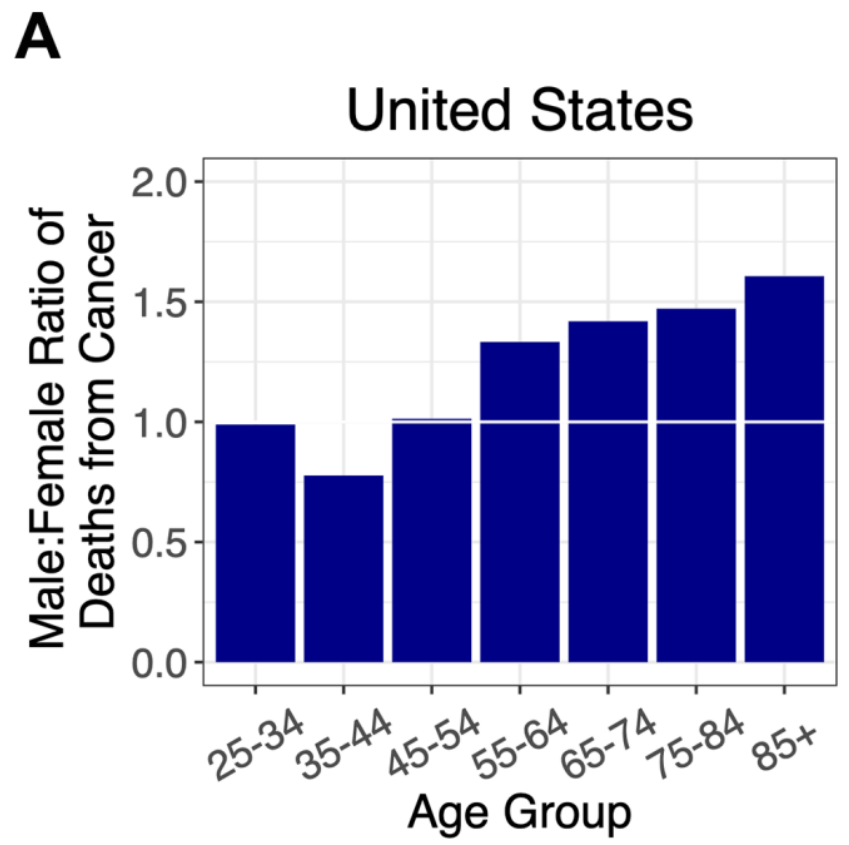

B

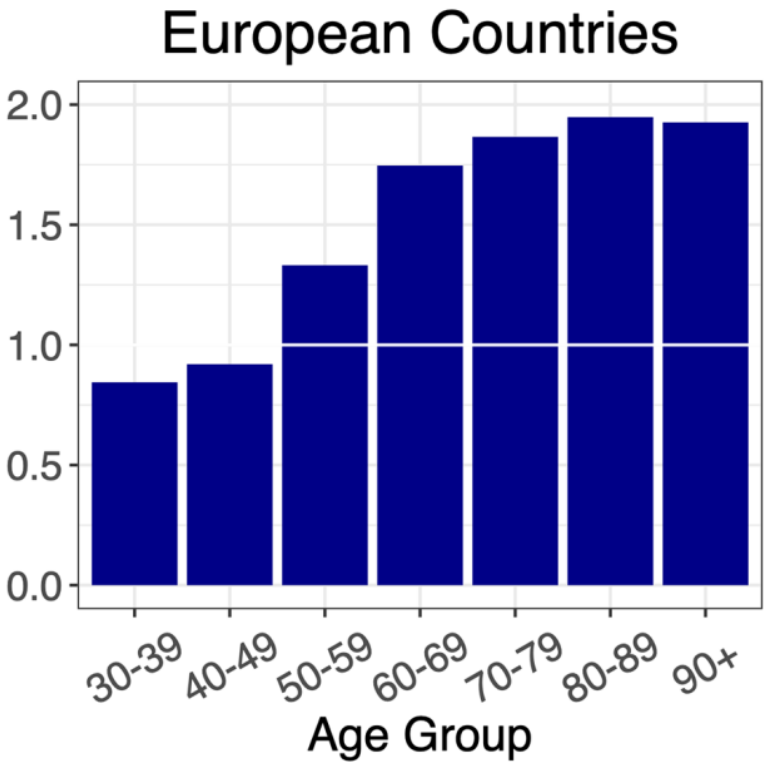

Figure 3. Ratios of male to female deaths from cancer (adjusted for population sex distribution) for (A) the US, and (B) combined ratios for the European countries: Italy, France, Spain, Germany, and the Netherlands. A 1:1 ratio is indicated by white horizontal lines.

A

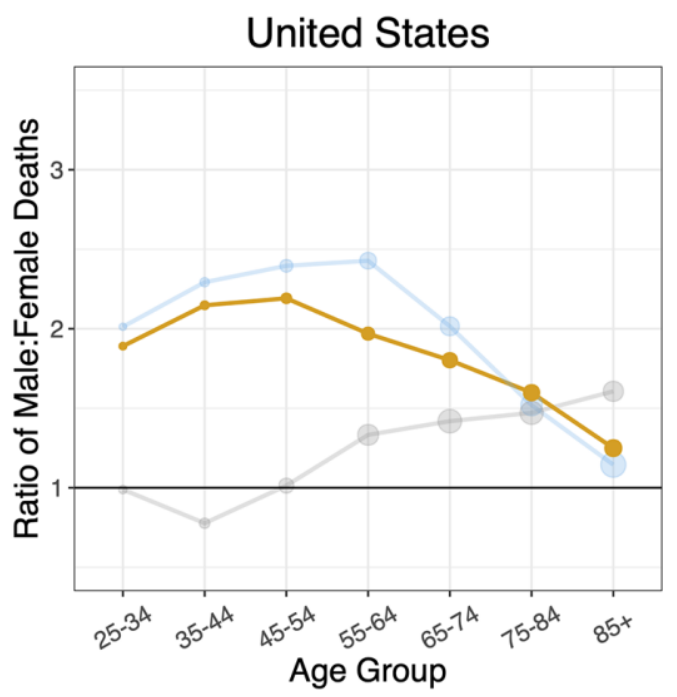

B

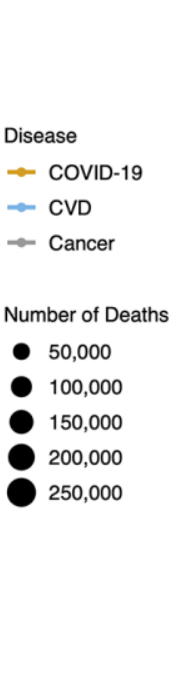

B

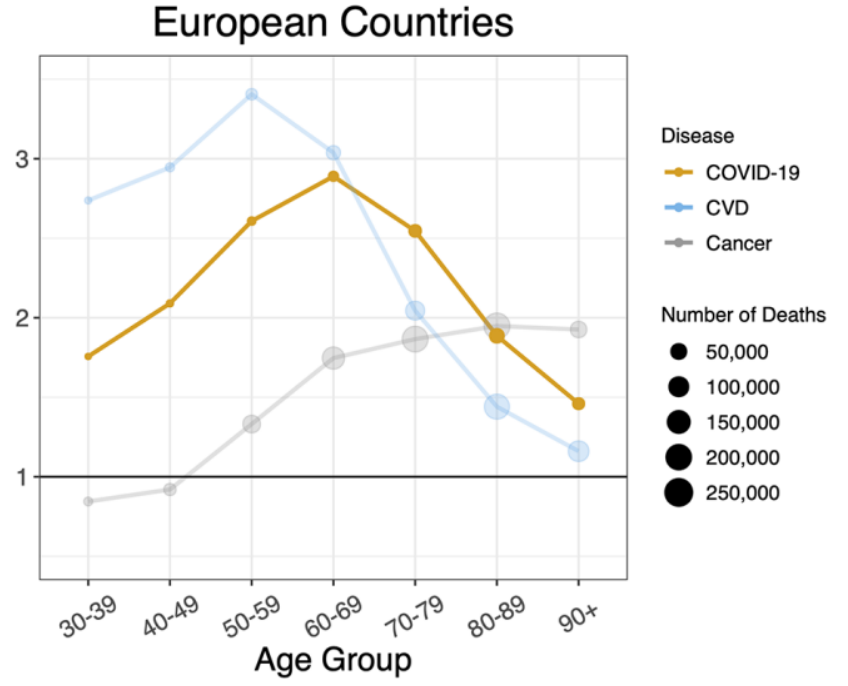

Figure 4. Sex ratios by age group in deaths for COVID-19, cardiovascular disease, and cancer in (A) the US and (B) the European Countries. A 1:1 ratio is indicated by black horizontal lines. Ratios are adjusted for sex distribution in the population at different age groups. 
(TMPRSS2) which activates the SARS-CoV-2 spike protein, facilitating SARS-CoV-2 entry into cells [24]. A recent study suggests that androgen-deprivation therapies lowers the risk of SARS-CoV-2 infection [25]. Since testosterone level decreases with age, a higher level of the hormone in young and middle age men may upregulate TMPRSS2 and thus contribute to the higher sex ratio for COVID-19 mortality before the sixth decade. That said, the knowledge of the effect of testosterone replacement therapy on the cardiovascular system is incomplete [26].

\section{$\mathrm{X}$ chromosome mosaicism}

The two $\mathrm{X}$ chromosomes provide an advantage related to $\mathrm{X}$-linked recessive diseases and other potentially deleterious mutations on the $\mathrm{X}$ chromosome. Random inactivation in utero of one $\mathrm{X}$ chromosome in each somatic cell engenders mosaicism that provides females with somatic cell diversity and the potential for selection of cells with an $\mathrm{X}$ chromosome harboring advantageous variant genes [27]. $X$ chromosome mosaicism might be particularly advantageous for surviving infectious disease, since the $\mathrm{X}$ chromosome harbors a number of genes engaged in immune function [28] - therefore having two copies of these genes confers additional immunological diversity in women [29]. In addition, $A C E 2$, the gene encoding angiotensinconverting enzyme 2, the cellular receptor for SARS$\mathrm{CoV}-2$ is on the $\mathrm{X}$ chromosome [30]. ACE2 variants might play a role in left ventricular hypertrophy that is often the outcome of hypertension [31], which tracks with age [32]. Some of these variants might also influence CVD [33], but no association of ACE2 polymorphisms with COVID-19 was observed thus far $[34,35]$.

\section{Limitations}

Limitations to this study include: (a) potential differences in reporting COVID-19 deaths between the countries analyzed; (b) the lack of linked individuallevel health and social databases; and (c) no information on the sex ratio of survival rates among people who acquired COVID-19. The latter would require, at a minimum, COVID-19 infection rates by age and sex in the general population (including asymptomatic infections) in order to determine whether there are sex- and age-based differences in survival from it.

Additionally, the study does not account for nuanced differences in the overall similar patterns for COVID-19 and CVD in the United States versus Europe. The peak sex ratio for COVID-19 occurs at an earlier age in the United States than Europe, and the sex ratio for CVD mortality is higher for Europe than the United States until the older age groups. Finally, we could not rule out that the lower sex ratios in COVID-19 and CVD for the oldest age groups were partly due to selection, in that males who survive to an exceptionally old age are "escapers" who hardly represent the general population of older males; in contrast, females who survive to such an old age might be "delayers" who largely represent the general population of older females [36, 37].

\section{CONCLUSIONS}

Our analyses show similar trends in the sex ratio by age of mortality from COVID-19 and from CVD. We propose that these findings might be due to some shared underlying biological mechanisms. Individual-level data are essential to examine potential shared mechanisms and to establish the potential contribution of CVD to the age patterning of the sex ratio of mortality in COVID19. We suggest that this line of research should be pursued and might uncover some of the causal mechanisms underlying COVID-19 mortality.

\section{MATERIALS AND METHODS}

We focused our analysis on the US, Italy, Spain, France, Germany, and the Netherlands because of (a) availability of their sex- and age-disaggregated mortality data from COVID-19, (b) data stratification into age group bins of 10 years or less, and (c) a high number of cumulative deaths from COVID-19 (sources are shown in Supplementary Table 1). COVID-19 mortality data were retrieved from national databases including the US Centers for Disease Control, the Italian National Institute of Health, the French Institute for Demographic Studies, the Spanish Ministry of Health, the German Federal Ministry of Health, and the Dutch Ministry for Health, Welfare and Sport. The data were retrieved on October $14^{\text {th }}, 2020$ and reflect the cumulative COVID-19 deaths in each country from the beginning of the pandemic up to dates between May $22^{\text {nd }}-$ October $13^{\text {th }} 2020$ (see Supplementary Tables 1 , 2 for details). (Note that after May $22^{\text {nd }}$, the Spanish Ministry of Health stopped providing sex- and agedisaggregated data on COVID-19 deaths [38].) In the US, data were included for age groups 25 years and older, and stratified into 10-year bins. For the European Countries, data were included for age groups 30 years and above and stratified into 10-year bins, and deaths were combined across the five countries by age group and sex. Age groups below 25 years were excluded from the analysis due to the smaller number of cases. The population at risk in each age group was retrieved from populationpyramid.net, a website that aggregates data from the United Nations Department of Economic and Social Affairs, Population Division. 
For the analysis of mortality from CVD and cancer, data were extracted from the World Health Organization Mortality Database (https://www.who.int/healthinfo/ mortality_data/en/), which collects national data on deaths from civil registries. The Database contains number of deaths by country, year, sex, age group and cause of death, and population size by country, year, sex and age group. The causes of death are categorized by International Classification of Disease (ICD)-10 codes. CVD deaths principally included deaths from coronary heart disease (ICD-10 codes I20-I25) or stroke (I60-I69) [39]. Cancer death data included deaths from all neoplasms (C00-C97, D00-D48) (Supplementary Table 3 ). The non-sex-biased cancers (Supplementary Figure 4) included those indicated by ICD-10 codes C00-C49, C64-D04, D09-D23, D30-D38, and D41-D48. Data was extracted for France (2014), Germany (2015), Italy (2015), Netherlands (2016), Spain (2015), and the US (2015), with the year of the most recent data available indicated in parentheses (Supplementary Tables 4-6). Population adjustment was done using population data from the same years as the mortality data. These population data were also extracted from the World Health Organization Mortality Database.

Plots and data visualizations were created using the ggplot2 package in R (https://ggplot2.tidyverse.org).

\section{AUTHOR CONTRIBUTIONS}

I.N., L.V., E.S. and A.A. provided substantial contributions to the design of the study. I.N. and A.A. wrote the first draft of the manuscript. All coauthors provided substantial contributions to the analysis and interpretation of data, critically reviewed the manuscript for important intellectual content, provided final approval of the version to be published, and agree to be accountable for all aspects of the work presented.

\section{CONFLICTS OF INTEREST}

The authors declare that they have no conflicts of interest.

\section{REFERENCES}

1. GlobalHealth5050. COVID-19 sex-disaggregated data tracker. 2020. (London. https://globalhealth5050. org/covid19/sex-disaggregated-data-tracker/: Global Health 50/50).

2. Agua-Agum J, Ariyarajah A, Blake IM, Cori A, Donnelly CA, Dorigatti I, Dye C, Eckmanns T, Ferguson NM, Fraser C, Garske T, Hinsley W, Jombart T, et al, and WHO Ebola Response Team. Ebola virus disease among male and female persons in West Africa. N Engl J Med. 2016; 374:96-98.

https://doi.org/10.1056/NEJMc1510305

PMID:26736011

3. Noymer A, Garenne M. The 1918 influenza epidemic's effects on sex differentials in mortality in the United States. Popul Dev Rev. 2000; 26:565-81. https://doi.org/10.1111/i.1728-4457.2000.00565.x PMID: 19530360

4. Quandelacy TM, Viboud C, Charu V, Lipsitch M, Goldstein E. Age- and sex-related risk factors for influenza-associated mortality in the United States between 1997-2007. Am J Epidemiol. 2014; 179:156-67. https://doi.org/10.1093/aje/kwt235 PMID:24190951

5. CDC. Coronavirus Disease 2019 (COVID-19): Older Adults. Atlanta: Centers for Disease Control and Prevention, U.S. Department of Health and Human Services. 2020.

6. CDC COVID-19 Response Team. Coronavirus disease 2019 in children - United States, February 12-April 2, 2020. MMWR Morb Mortal Wkly Rep. 2020; 69:422-26. https://doi.org/10.15585/mmwr.mm6914e4 PMID: $\underline{2271728}$

7. Shang $M$, Blanton L, Brammer L, Olsen SJ, Fry AM. Influenza-associated pediatric deaths in the United States, 2010-2016. Pediatrics. 2018; 141:e20172918. https://doi.org/10.1542/peds.2017-2918 PMID:29440502

8. CDC. Archived Estimated Influenza Illnesses, Medical visits, Hospitalizations, and Deaths in the United States - 2017-2018 influenza season. National Center for Immunization and Respiratory Diseases (NCIRD), Centers for Disease Control and Prevention, U.S. Department of Health and Human Services. 2019.

9. Taubenberger JK, Morens DM. 1918 influenza: the mother of all pandemics. Emerg Infect Dis. 2006; 12:15-22.

https://doi.org/10.3201/eid1201.050979 PMID:16494711

10. Bautista E, Chotpitayasunondh T, Gao Z, Harper SA, Shaw M, Uyeki TM, Zaki SR, Hayden FG, Hui DS, Kettner JD, Kumar A, Lim M, Shindo N, et al, and Writing Committee of the WHO Consultation on Clinical Aspects of Pandemic (H1N1) 2009 Influenza. Clinical aspects of pandemic 2009 influenza a (H1N1) virus infection. N Engl J Med. 2010; 362:1708-19. https://doi.org/10.1056/NEJMra1000449 PMID:20445182

11. Guzik TJ, Mohiddin SA, Dimarco A, Patel V, Savvatis K, Marelli-Berg FM, Madhur MS, Tomaszewski M, Maffia P, D’Acquisto F, Nicklin SA, Marian AJ, Nosalski R, et al. COVID-19 and the cardiovascular system: implications 
for risk assessment, diagnosis, and treatment options. Cardiovasc Res. 2020; 116:1666-87.

https://doi.org/10.1093/cvr/cvaa106 PMID:32352535

12. Blagosklonny MV. From causes of aging to death from COVID-19. Aging (Albany NY). 2020; 12:10004-21.

https://doi.org/10.18632/aging.103493

PMID:32534452

13. 2016 GHE. Deaths by Cause, Age, Sex, by Country and by Region, 2000-2016. Geneva: World Health Organization. 2018.

14. Nishiga $M$, Wang DW, Han $Y$, Lewis DB, Wu JC. COVID-19 and cardiovascular disease: from basic mechanisms to clinical perspectives. Nat Rev Cardiol. 2020; 17:543-58.

https://doi.org/10.1038/s41569-020-0413-9

PMID:32690910

15. Guan WJ, Ni ZY, Hu Y, Liang WH, Ou CQ, He JX, Liu L, Shan H, Lei CL, Hui DS, Du B, Li L, Zeng G, et al, and China Medical Treatment Expert Group for Covid-19. Clinical characteristics of coronavirus disease 2019 in China. N Engl J Med. 2020; 382:1708-20.

https://doi.org/10.1056/NEJMoa2002032

PMID:32109013

16. Ostchega $Y$, Fryar CD, Nwankwo T, Nguyen DT. Hypertension prevalence among adults aged 18 and over: United States, 2017-2018. NCHS Data Brief. 2020; 264:1-8.

PMID:32487290

17. Man JJ, Beckman JA, Jaffe IZ. Sex as a biological variable in atherosclerosis. Circ Res. 2020; 126:1297-319.

https://doi.org/10.1161/CIRCRESAHA.120.315930

PMID:32324497

18. Morselli E, Santos RS, Criollo A, Nelson MD, Palmer BF, Clegg DJ. The effects of oestrogens and their receptors on cardiometabolic health. Nat Rev Endocrinol. 2017; 13:352-64.

https://doi.org/10.1038/nrendo.2017.12

PMID:28304393

19. Brown SB, Hankinson SE. Endogenous estrogens and the risk of breast, endometrial, and ovarian cancers. Steroids. 2015; 99:8-10.

https://doi.org/10.1016/j.steroids.2014.12.013 PMID:25555473

20. Spagnolo PA, Manson JE, Joffe H. Sex and gender differences in health: what the COVID-19 pandemic can teach us. Ann Intern Med. 2020; 173:385-86. https://doi.org/10.7326/M20-1941 PMID:32384135

21. Hall OJ, Klein SL. Progesterone-based compounds affect immune responses and susceptibility to infections at diverse mucosal sites. Mucosal Immunol. 2017; 10:1097-107. https://doi.org/10.1038/mi.2017.35 PMID:28401937

22. Reynolds RF, Obermeyer CM. Age at natural menopause in Spain and the United States: results from the DAMES project. Am J Hum Biol. 2005; 17:331-40.

https://doi.org/10.1002/ajhb.20121 PMID:15849704

23. Lin B, Ferguson C, White JT, Wang S, Vessella R, True LD, Hood L, Nelson PS. Prostate-localized and androgen-regulated expression of the membranebound serine protease TMPRSS2. Cancer Res. 1999; 59:4180-84.

PMID:10485450

24. Hoffmann $M$, Kleine-Weber $H$, Schroeder $S$, Krüger $N$, Herrler T, Erichsen S, Schiergens TS, Herrler G, Wu NH, Nitsche A, Müller MA, Drosten C, Pöhlmann S. SARSCoV-2 cell entry depends on ACE2 and TMPRSS2 and is blocked by a clinically proven protease inhibitor. Cell. 2020; 181:271-80.e8. https://doi.org/10.1016/i.cell.2020.02.052 PMID:32142651

25. Montopoli $M$, Zumerle $S$, Vettor R, Rugge $M$, Zorzi $M$, Catapano CV, Carbone GM, Cavalli A, Pagano F, Ragazzi E, Prayer-Galetti T, Alimonti A. Androgen-deprivation therapies for prostate cancer and risk of infection by SARS-CoV-2: a population-based study ( $\mathrm{N}=4532)$. Ann Oncol. 2020; 31:1040-45.

https://doi.org/10.1016/j.annonc.2020.04.479 PMID:32387456

26. Gagliano-Jucá T, Basaria S. Testosterone replacement therapy and cardiovascular risk. Nat Rev Cardiol. 2019; 16:555-74. https://doi.org/10.1038/s41569-019-0211-4 PMID: $\underline{1123340}$

27. Migeon BR. Why females are mosaics, $x$-chromosome inactivation, and sex differences in disease. Gend Med. 2007; 4:97-105. https://doi.org/10.1016/s1550-8579(07)80024-6 PMID:17707844

28. Klein SL, Flanagan KL. Sex differences in immune responses. Nat Rev Immunol. 2016; 16:626-38. https://doi.org/10.1038/nri.2016.90 PMID:27546235

29. Libert C, Dejager L, Pinheiro I. The X chromosome in immune functions: when a chromosome makes the difference. Nat Rev Immunol. 2010; 10:594-604. https://doi.org/10.1038/nri2815 PMID:20651746

30. Devaux CA, Rolain JM, Raoult D. ACE2 receptor polymorphism: susceptibility to SARS-CoV-2, hypertension, multi-organ failure, and COVID-19 disease outcome. J Microbiol Immunol Infect. 2020; 53:425-35. 
https://doi.org/10.1016/i.jmii.2020.04.015

PMID:32414646

31. Lieb W, Graf J, Götz A, König IR, Mayer B, Fischer M, Stritzke J, Hengstenberg C, Holmer SR, Döring A, Löwel $\mathrm{H}$, Schunkert H, Erdmann J. Association of angiotensinconverting enzyme 2 (ACE2) gene polymorphisms with parameters of left ventricular hypertrophy in men. Results of the MONICA augsburg echocardiographic substudy. J Mol Med (Berl). 2006; 84:88-96.

https://doi.org/10.1007/s00109-005-0718-5

PMID:16283142

32. Cuspidi C, Meani S, Sala C, Valerio C, Negri F, Mancia G. Age related prevalence of severe left ventricular hypertrophy in essential hypertension: echocardiographic findings from the ETODH study. Blood Press. 2012; 21:139-45.

https://doi.org/10.3109/08037051.2012.668662 PMID:22416806

33. Burrell LM, Harrap SB, Velkoska E, Patel SK. The ACE2 gene: its potential as a functional candidate for cardiovascular disease. Clin Sci (Lond). 2013; 124:65-76. https://doi.org/10.1042/CS20120269 PMID:23013041

34. Asselta R, Paraboschi EM, Mantovani A, Duga S. ACE2 and TMPRSS2 variants and expression as candidates to sex and country differences in COVID-19 severity in Italy. Aging (Albany NY). 2020; 12:10087-98. https://doi.org/10.18632/aging.103415 PMID:32501810

35. Lopera Maya EA, van der Graaf A, Lanting $P$, van der Geest M, Fu J, Swertz M, Franke L, Wijmenga C, Deelen
P, Zhernakova A, Sanna S, and Lifelines Cohort Study. Lack of association between genetic variants at ACE2 and TMPRSS2 genes involved in SARS-CoV-2 infection and human quantitative phenotypes. Front Genet. 2020; $11: 613$.

https://doi.org/10.3389/fgene.2020.00613

PMID:32582302

36. Perls TT. Male centenarians: how and why are they different from their female counterparts? J Am Geriatr Soc. 2017; 65:1904-06.

https://doi.org/10.1111/jgs.14978

PMID:28586117

37. Ailshire JA, Beltrán-Sánchez $\mathrm{H}$, Crimmins EM. Becoming centenarians: disease and functioning trajectories of older US adults as they survive to 100. J Gerontol A Biol Sci Med Sci. 2015; 70:193-201.

https://doi.org/10.1093/gerona/glu124

PMID:25136001

38. Trias-Llimós S, Alustiza A, Prats C, Tobias A, Riffe T. The need for detailed COVID-19 data in Spain. Lancet Public Health. 2020; 5:e576.

https://doi.org/10.1016/S2468-2667(20)30234-6 PMID:33045185

39. Bots SH, Peters SA, Woodward M. Sex differences in coronary heart disease and stroke mortality: a global assessment of the effect of ageing between 1980 and 2010. BMJ Glob Health. 2017; 2:e000298. https://doi.org/10.1136/bmjgh-2017-000298 PMID:28589033 


\section{SUPPLEMENTARY MATERIALS}

\section{Supplementary Figures}

A

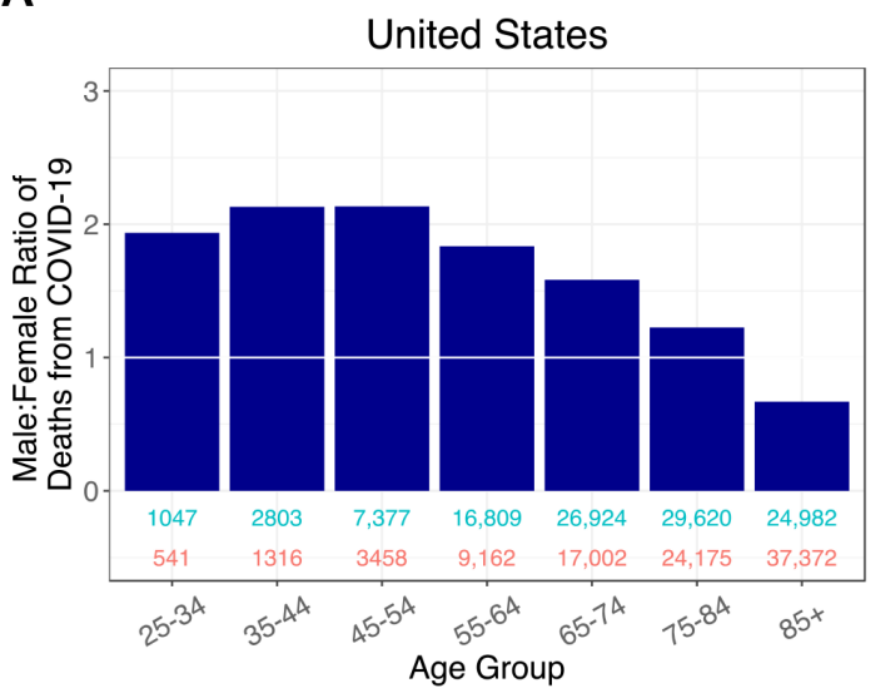

B

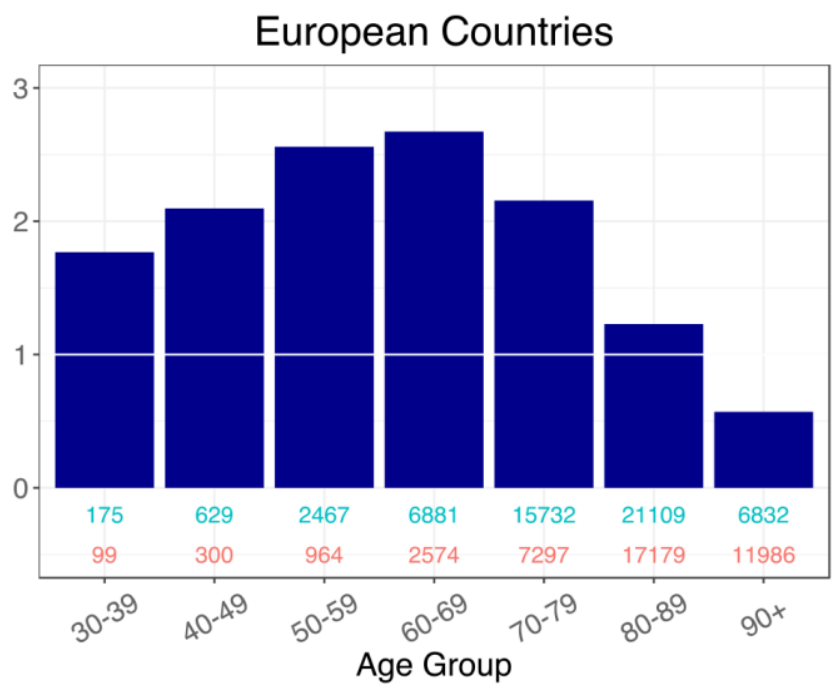

Supplementary Figure 1. Ratios of male to female deaths from COVID-19 (raw data) for the (A) United States, and (B) combined ratios for five European countries: Italy, France, Spain, Germany, and the Netherlands. A 1:1 ratio is indicated by white markers. Numbers below plots indicate number of male deaths (turquoise) and female deaths (orange).

A

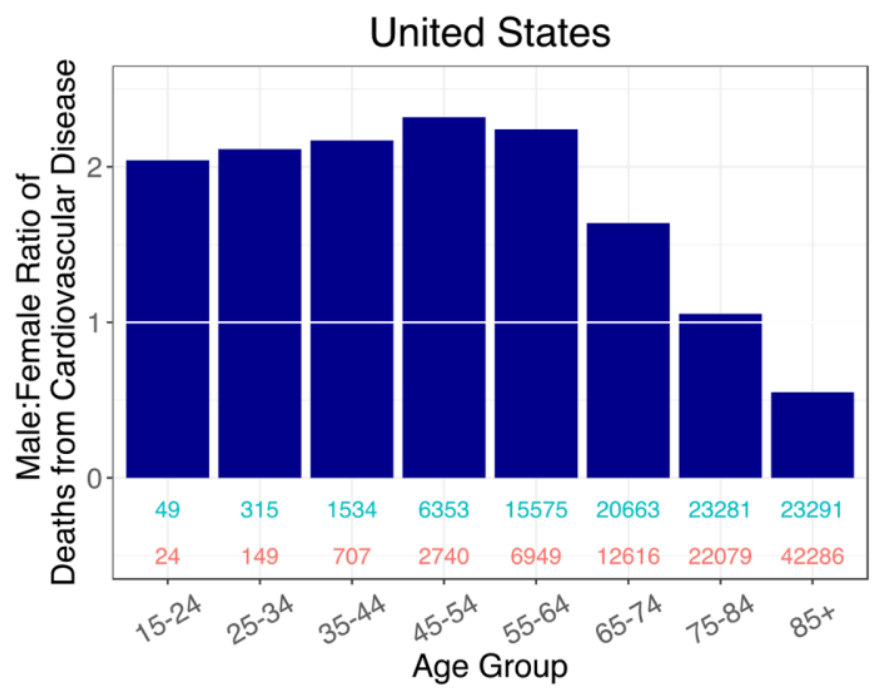

B

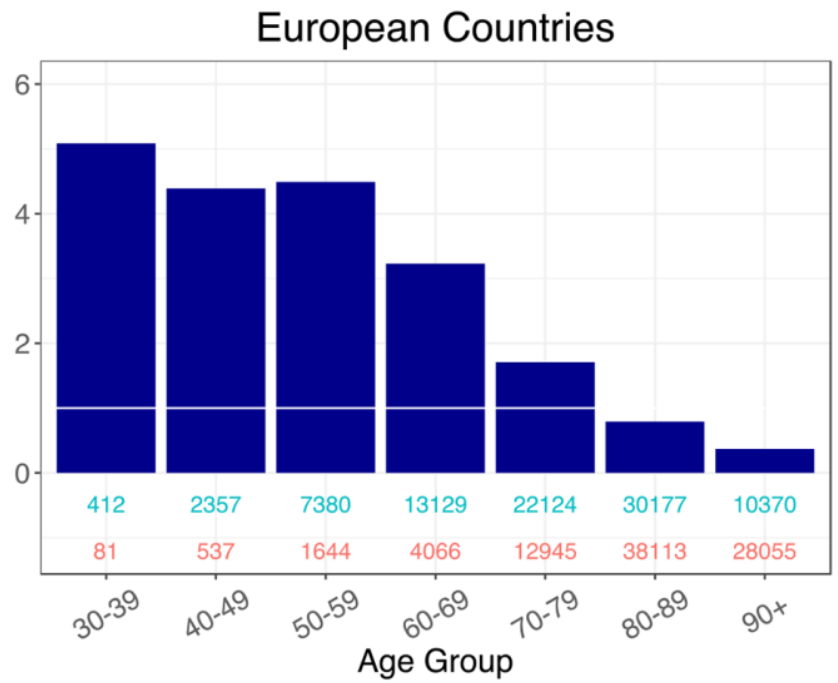

Supplementary Figure 2. Ratios of male to female deaths from cardiovascular disease (raw data) for the (A) United States, and (B) combined ratios for five European countries: Italy, France, Spain, Germany, and the Netherlands. A 1:1 ratio is indicated by white markers. Numbers below plots indicate number of male deaths (turquoise) and female deaths (orange). Note that $y$-axes have different scales. 
A

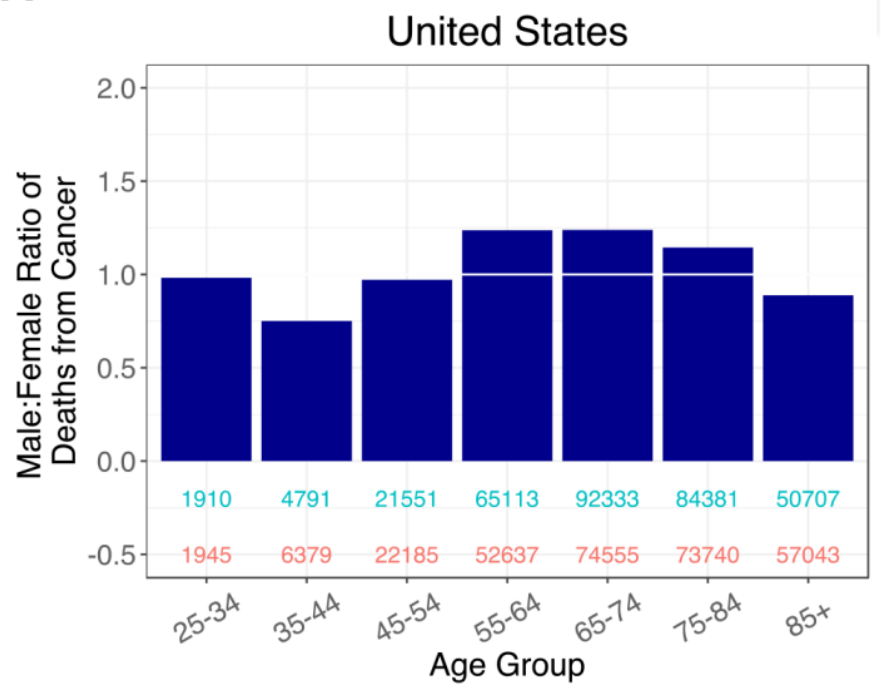

B

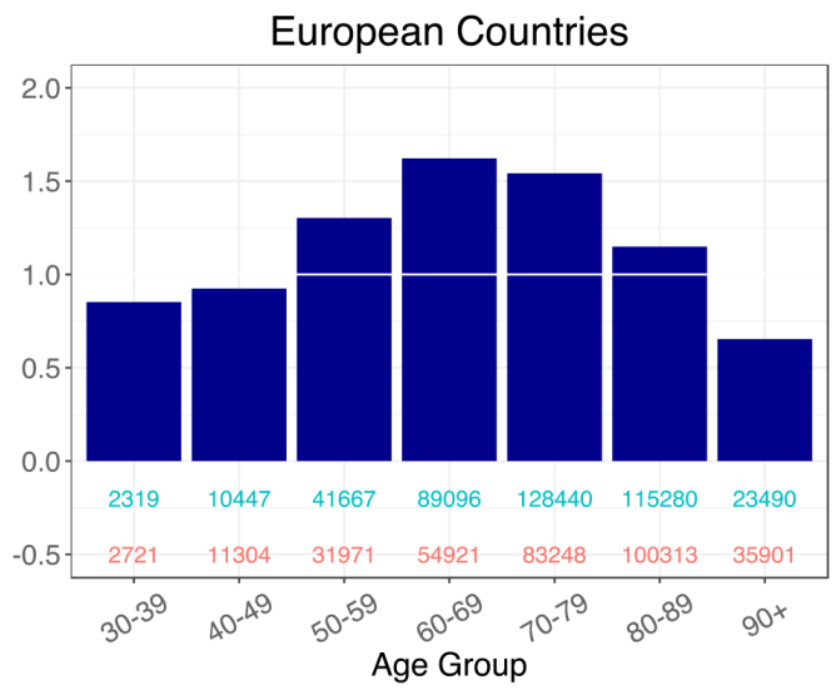

Supplementary Figure 3. Ratios of male to female deaths from cancer (raw data) for the (A) United States, and (B) combined ratios for five European countries: Italy, France, Spain, Germany, and the Netherlands. A 1:1 ratio is indicated by white markers. Numbers below plots indicate number of male deaths (turquoise) and female deaths (orange).

A

United States

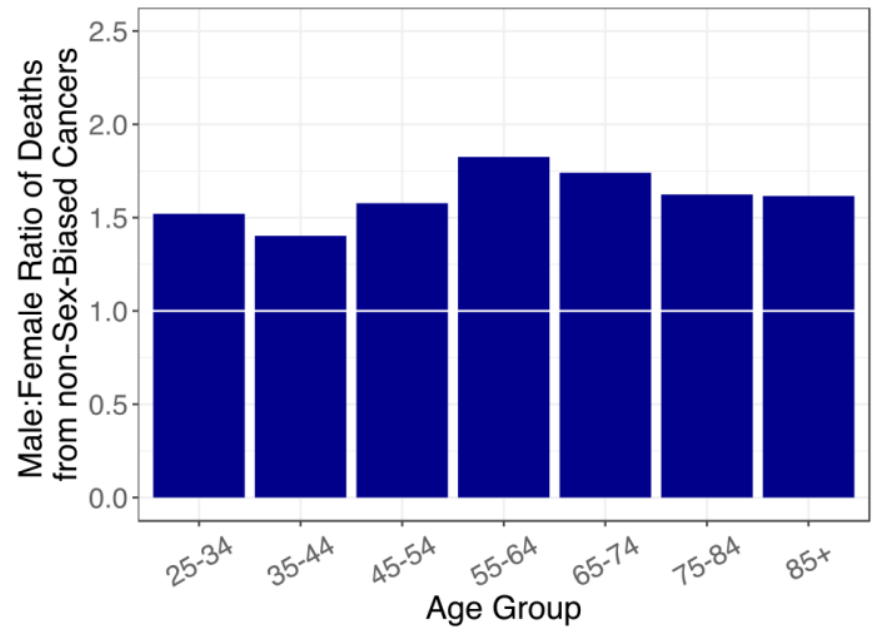

B

European Countries

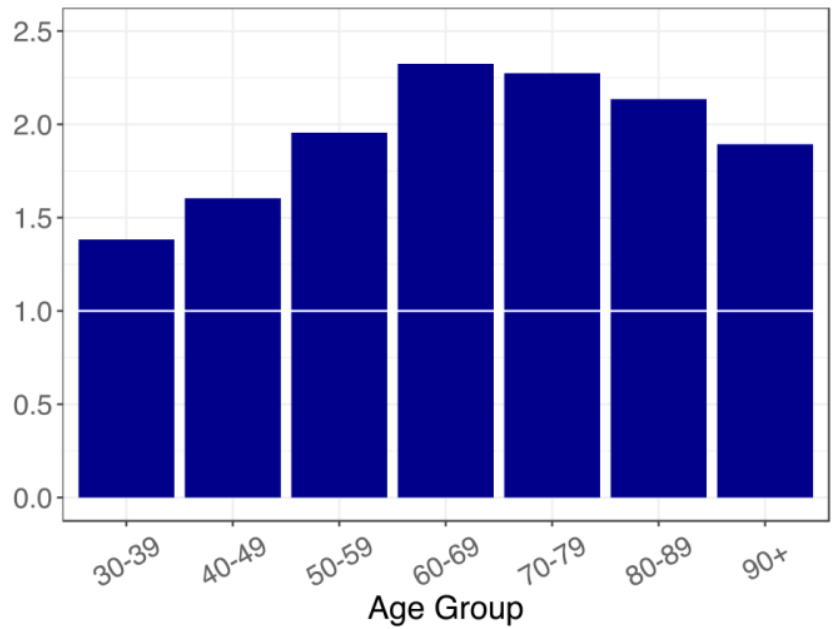

Supplementary Figure 4. Ratios of male to female deaths from non-sex-biased cancers (adjusted for population sex distribution) for the (A) United States, and (B) combined ratios for five European countries: Italy, France, Spain, Germany, and the Netherlands. A 1:1 ratio is indicated by white markers. 


\section{Supplementary Tables}

Please browse Full Text version to see the data of Supplementary Table 3.

Supplementary Table 1. Sources for COVID-19 deaths data.

\begin{tabular}{lccc}
\hline Country & \multicolumn{1}{c}{ Website } & Date updated & Date accessed \\
\hline United States & https://data.cdc.gov/ & Oct 102020 & Oct 142020 \\
Italy & https://www.epicentro.iss.it/ & Oct 42020 & Oct 142020 \\
France & $\underline{\text { https://dc-covid.site.ined.fr/ }}$ & Oct 82020 & Oct 142020 \\
Spain & $\underline{\text { https://www.mscbs.gob.es/ }}$ & May 22 2020 & Oct 142020 \\
Germany & $\underline{\text { https://www.rki.de/ }}$ & Oct 132020 & Oct 142020 \\
Netherlands & https://www.rivm.nl/ & Oct 13 2020 & Oct 14 2020 \\
\hline
\end{tabular}

Supplementary Table 2. Raw data for COVID-19 deaths stratified by age and sex.

\begin{tabular}{|c|c|c|c|c|c|c|c|c|c|c|c|}
\hline \multirow{11}{*}{$\begin{array}{l}\text { United } \\
\text { States }\end{array}$} & Age group & Male & Female & \multirow{11}{*}{ Italy } & Age group & Males & Females & \multirow{11}{*}{ France } & Age group & Male & Female \\
\hline & $0-4$ & 22 & 15 & & $0-9$ & 1 & 3 & & $0-9$ & 2 & 1 \\
\hline & $5-14$ & 24 & 13 & & $10-19$ & 0 & 0 & & $10-19$ & 2 & 2 \\
\hline & $15-24$ & 230 & 144 & & $20-29$ & 12 & 3 & & $20-29$ & 18 & 9 \\
\hline & $25-34$ & 1047 & 541 & & $30-39$ & 46 & 24 & & $30-39$ & 61 & 42 \\
\hline & $35-44$ & 2803 & 1316 & & $40-49$ & 229 & 89 & & $40-49$ & 178 & 94 \\
\hline & $45-54$ & 7377 & 3458 & & $50-59$ & 959 & 302 & & $50-59$ & 667 & 324 \\
\hline & $55-64$ & 16809 & 9162 & & $60-69$ & 2742 & 864 & & $60-69$ & 1803 & 751 \\
\hline & $65-74$ & 26924 & 17002 & & $70-79$ & 6505 & 2892 & & $70-79$ & 3321 & 1506 \\
\hline & $75-84$ & 29620 & 24175 & & $80-89$ & 8047 & 6677 & & $80-89$ & 4600 & 3415 \\
\hline & $85+$ & 24982 & 37372 & & $90+$ & 2101 & 4511 & & $90+$ & 1989 & 2741 \\
\hline \multirow{11}{*}{ Spain } & Age group & Male & Female & \multirow{11}{*}{ Germany } & Age group & Males & Females & \multirow{11}{*}{ Netherlands } & Age group & Male & Female \\
\hline & $0-9$ & 1 & 1 & & $0-9$ & 0 & 1 & & $0-9$ & 0 & 0 \\
\hline & $10-19$ & 3 & 2 & & $10-19$ & 1 & 0 & & $10-19$ & 1 & 0 \\
\hline & $20-29$ & 15 & 9 & & $20-29$ & 8 & 3 & & $20-29$ & 3 & 0 \\
\hline & $30-39$ & 42 & 21 & & $30-39$ & 18 & 8 & & $30-39$ & 8 & 4 \\
\hline & $40-49$ & 140 & 77 & & $40-49$ & 60 & 24 & & $40-49$ & 22 & 16 \\
\hline & $50-59$ & 467 & 192 & & $50-59$ & 265 & 96 & & $50-59$ & 109 & 50 \\
\hline & $60-69$ & 1283 & 539 & & $60-69$ & 691 & 244 & & $60-69$ & 362 & 176 \\
\hline & $70-79$ & 3326 & 1564 & & $70-79$ & 1467 & 708 & & $70-79$ & 1113 & 627 \\
\hline & $80-89$ & 4655 & 3792 & & $80-89$ & 2226 & 2006 & & $80-89$ & 1581 & 1289 \\
\hline & $90+$ & 1681 & 2723 & & $90+$ & 617 & 1185 & & $90+$ & 444 & 826 \\
\hline
\end{tabular}

Supplementary Table 3. International classification of diseases (ICD)-10 codes for causes of death. Causes of death marked with an ' $X$ ' in column 2 were not included in the analysis of non-sex-biased cancers. 
Supplementary Table 4. Raw data for cardiovascular disease deaths stratified by age and sex.

\begin{tabular}{lcccccccccccc}
\hline Country & Year & Sex & $\mathbf{0 - 9}$ & $\mathbf{1 0 - 1 9}$ & $\mathbf{2 0 - 2 9}$ & $\mathbf{3 0 - 3 9}$ & $\mathbf{4 0 - 4 9}$ & $\mathbf{5 0 - 5 9}$ & $\mathbf{6 0 - 6 9}$ & $\mathbf{7 0 - 7 9}$ & $\mathbf{8 0 - 8 9}$ & $\mathbf{9 0 +}$ \\
\hline Netherlands & 2016 & $\mathrm{~F}$ & 1 & 0 & 4 & 15 & 92 & 248 & 600 & 1523 & 3953 & 2715 \\
Netherlands & 2016 & $\mathrm{M}$ & 0 & 1 & 9 & 26 & 150 & 524 & 1371 & 2414 & 3410 & 1091 \\
Germany & 2015 & $\mathrm{~F}$ & 7 & 11 & 33 & 86 & 488 & 1654 & 4004 & 15749 & 41202 & 30116 \\
Germany & 2015 & $\mathrm{M}$ & 6 & 8 & 52 & 247 & 1473 & 5720 & 11281 & 27166 & 35472 & 10437 \\
Italy & 2015 & $\mathrm{~F}$ & 11 & 6 & 23 & 73 & 278 & 828 & 2300 & 8775 & 32644 & 28310 \\
Italy & 2015 & $\mathrm{M}$ & 10 & 11 & 39 & 207 & 954 & 2698 & 6127 & 13858 & 26324 & 11478 \\
Spain & 2015 & $\mathrm{~F}$ & 1 & 2 & 10 & 66 & 245 & 583 & 1288 & 4087 & 14197 & 10084 \\
Spain & 2015 & $\mathrm{M}$ & 5 & 10 & 30 & 160 & 780 & 2286 & 4011 & 7396 & 12333 & 4629 \\
France & 2014 & $\mathrm{~F}$ & 9 & 7 & 17 & 55 & 298 & 710 & 1449 & 3778 & 13798 & 11762 \\
France & 2014 & $\mathrm{M}$ & 11 & 6 & 31 & 175 & 790 & 2181 & 4417 & 6500 & 12377 & 5088 \\
\hline Country & Year & Sex & $\mathbf{0 - 4}$ & $\mathbf{5 - 1 4}$ & $\mathbf{1 5 - 2 4}$ & $\mathbf{2 5 - 3 4}$ & $\mathbf{3 5 - 4 4}$ & $\mathbf{4 5 - 5 4}$ & $\mathbf{5 5 - 6 4}$ & $\mathbf{6 5 - 7 4}$ & $\mathbf{7 5 - 8 4}$ & $\mathbf{8 5 +}$ \\
\hline United States of America & 2015 & $\mathrm{~F}$ & 63 & 45 & 112 & 515 & 2069 & 7714 & 18751 & 32406 & 58308 & 119546 \\
United States of America & 2015 & $\mathrm{M}$ & 86 & 51 & 187 & 1029 & 4585 & 17712 & 42256 & 57005 & 68928 & 75730 \\
\hline
\end{tabular}

Supplementary Table 5. Raw data for cancer deaths (all) stratified by age and sex.

\begin{tabular}{lccccccccc}
\hline Country & Year & Sex & $\mathbf{3 0 - 3 9}$ & $\mathbf{4 0 - 4 9}$ & $\mathbf{5 0 - 5 9}$ & $\mathbf{6 0 - 6 9}$ & $\mathbf{7 0 - 7 9}$ & $\mathbf{8 0 - 8 9}$ & $\mathbf{9 0 +}$ \\
\hline Netherlands & 2016 & $\mathrm{M}$ & 115 & 607 & 2178 & 5986 & 8205 & 6844 & 1324 \\
Netherlands & 2016 & $\mathrm{~F}$ & 201 & 698 & 2452 & 4802 & 5789 & 5700 & 1893 \\
Germany & 2015 & $\mathrm{M}$ & 592 & 2960 & 13167 & 26374 & 45208 & 32306 & 5315 \\
Germany & 2015 & $\mathrm{~F}$ & 723 & 3191 & 10623 & 18174 & 32371 & 31501 & 10438 \\
Italy & 2015 & $\mathrm{M}$ & 541 & 2302 & 7636 & 19063 & 32100 & 31181 & 6175 \\
Italy & 2015 & $\mathrm{~F}$ & 613 & 2707 & 6776 & 12629 & 20792 & 26554 & 9083 \\
Spain & 2015 & $\mathrm{M}$ & 468 & 1885 & 7476 & 14435 & 19171 & 19631 & 4339 \\
Spain & 2015 & $\mathrm{~F}$ & 483 & 1972 & 4891 & 6883 & 9573 & 14533 & 5120 \\
France & 2014 & $\mathrm{M}$ & 603 & 2693 & 11210 & 23238 & 23756 & 25318 & 6337 \\
France & 2014 & $\mathrm{~F}$ & $\mathbf{7 0 1}$ & 2736 & 7229 & 12433 & 14723 & 22025 & 9367 \\
\hline Country & Year & Sex & $\mathbf{2 5 - 3 4}$ & $\mathbf{3 5 - 4 4}$ & $\mathbf{4 5 - 5 4}$ & $\mathbf{5 5 - 6 4}$ & $\mathbf{6 5 - 7 4}$ & $\mathbf{7 5 - 8 4}$ & $\mathbf{8 5 +}$ \\
\hline United States of America & 2015 & $\mathrm{M}$ & 1910 & 4791 & 21551 & 65113 & 92333 & 84381 & 50707 \\
United States of America & 2015 & $\mathrm{~F}$ & 1945 & 6379 & 22185 & 52637 & 74555 & 73740 & 57043 \\
\hline
\end{tabular}

Supplementary Table 6. Raw data for cancer deaths (excluding sex-biased cancers) stratified by age and sex.

\begin{tabular}{lccccccccc}
\hline Country & Year & Sex & $\mathbf{3 0 - 3 9}$ & $\mathbf{4 0 - 4 9}$ & $\mathbf{5 0 - 5 9}$ & $\mathbf{6 0 - 6 9}$ & $\mathbf{7 0 - 7 9}$ & $\mathbf{8 0 - 8 9}$ & $\mathbf{9 0 +}$ \\
\hline Netherlands & 2016 & $\mathrm{M}$ & 111 & 597 & 2106 & 5575 & 7294 & 5686 & 1042 \\
Netherlands & 2016 & $\mathrm{~F}$ & 117 & 415 & 1684 & 3651 & 4567 & 4560 & 1455 \\
Germany & 2015 & $\mathrm{M}$ & 563 & 2895 & 12726 & 24698 & 40057 & 26589 & 3906 \\
Germany & 2015 & $\mathrm{~F}$ & 425 & 1814 & 7037 & 13125 & 23680 & 23879 & 7973 \\
Italy & 2015 & $\mathrm{M}$ & 520 & 2254 & 7475 & 18327 & 29942 & 27450 & 4929 \\
Italy & 2015 & $\mathrm{~F}$ & 370 & 1480 & 4328 & 9010 & 15972 & 21157 & 7176 \\
Spain & 2015 & $\mathrm{M}$ & 449 & 1853 & 7334 & 13858 & 17676 & 16814 & 3345 \\
Spain & 2015 & $\mathrm{~F}$ & 278 & 1094 & 3326 & 4914 & 7335 & 11435 & 4036 \\
France & 2014 & $\mathrm{M}$ & 576 & 2659 & 11009 & 22242 & 21735 & 21342 & 4744 \\
France & 2014 & $\mathrm{~F}$ & 400 & 1563 & 4864 & 8524 & 10504 & 16682 & 7284 \\
\hline Country & Year & Sex & $\mathbf{2 5 - 3 4}$ & $\mathbf{3 5 - 4 4}$ & $\mathbf{4 5 - 5 4}$ & $\mathbf{5 5 - 6 4}$ & $\mathbf{6 5 - 7 4}$ & $\mathbf{7 5 - 8 4}$ & $\mathbf{8 5 +}$ \\
\hline United States of America & 2015 & $\mathrm{M}$ & 1800 & 4686 & 21006 & 62199 & 85570 & 74508 & 40933 \\
United States of America & 2015 & $\mathrm{~F}$ & 1192 & 3456 & 13893 & 36710 & 56325 & 58977 & 45779 \\
\hline
\end{tabular}

